\section{DANDELION}

postgraduate arts journal \& research network

VOLUME 5 NUMBER 2 SPRING 2015
DAN STRUTT is a 2013 graduate from Goldsmiths College. He was AHRC funded, under the supervision of Dr Rachel O. Moore and Dr Pasi Valiaho to complete his project 'The Difference the Digital Makes: The Affective Synthesis of Reality by Digital Screen Media'. His research interests include film, digital humanities, new media philosophy, affect theory, aesthetics and cultural theory. $\mathrm{He}$ is currently an associate lecturer in the Media and Communications department at Goldsmiths College and is engaged in research projects with both CREATe and Creativeworks London.

Article

d.strutt@gold.ac.uk

\title{
Digital Grammatisation: \\ The Affective Synthesis of Reality by Digital Screen Media
}

\author{
Dr Daniel Strutt
}

IN THIS ARTICLE I AIM TO SUGGeST that contemporary digital visual media fundamentally affect our corporeal intuition of reality - our inhabited, affective sense of the world and our presence and interactions within it. This is the digital image as seen projected on the multiple screens that surround us in the urban environment, but also in Google glasses, in virtual reality goggles (already making a return within the gaming world), projected onto buildings (through practices such as digital projection mapping), and even in 3D printing (thought of here as image projection within a three dimensional, volumetric screen). Giving several examples, I will work toward the thesis that due to the relative (im)materiality of the digital image we come to metaphorically infer that the materiality of reality is of or like data. This metaphor works around the idea that the stable forms and metaphysical constants of the real world are subject to fluctuation, transformation and change. Through a lay knowledge of the ambiguities of theoretical physics this understanding of reality seems to arrive at being more than just a metaphor - as the digital image is wrapped around and superimposed upon the real world in complex ways (an 'augmented reality') it moves towards being a non-thought intuition held deep within the affective body.

The many different technical forms of representation of the world both project our imagination, and also shape our capacity to imagine, 'revealing' the world in a specific way. Walter Benjamin noted in Work of Art in the Age of Mechanical Reproducibility that it is in a state of non-attentive distraction, within the technological situation of a specific historical moment, that the mass 'absorbs' the skills demanded of our perception at that time. 'This 'absorption' 
of perceptual, intuitive skills through digital visual media functions primarily through affective, immersive, operational and interactive means. As such I state that at a time when the physical sciences contemplate the metaphysical ambiguities of multi-dimensionality, holographic universe theory ${ }^{2}$ and neuroplasticity, this comes in tandem or works synergistically with the technical capacity of digital media to reflect and refract the world in equivalent terms.

One might assume a causal relationship between these two ostensibly separate disciplines (that is the arts [including philosophic arts] and science) that our capacity to represent and thereby imagine inflects our scientific progress, or inversely that media merely attempts, often poorly, to make concrete images out of abstract scientific concepts. For this reason my theoretical starting point is Heidegger's essay The Question Concerning Technology which I use to break down the fundamental division between these spheres. $^{3}$

His is of course an expanded notion of technology as technics or techné, encompassing all tools, languages, institutions and disciplines, rather than specific machines, though this does not exclude actual and tangible machines. To summarise my use of this analysis I make three points.

a. That technologies are most often perceived in an instrumental mode, but they in fact shape us as subjects. Media in this way is seen as a tool for the representation and sharing of experience, meanwhile these media representations are actually shaping our experience, our capacity for experience, and the ways we are able to reflect upon that experience.

b. Both scientific technologies and the more poetic/philosophical arts are two sides of the same coin; they are, as techné, both modes of revealing the world to us. In this sense they both form mental schema for thinking about the world as being a certain way - they are both crafts, which provide models for access to underlying truths about reality.

c. Heidegger's central point is that the essence of technology, the modes in which technologies shape us (enframing) become invisible to us and we fail to be able to understand this essence. For Heidegger only art can shatter these bonds as an alternate form of revealing - as a 'saving power'. ${ }^{4}$ He does however note in an often forgotten 'other possibility', that: 'the frenziedness of technology may entrench itself everywhere to such an extent that someday, throughout everything technological, the essence of technology may come to presence in the coming to pass of truth'. ${ }^{5}$ I.e. that through technology's complete saturation of life, that it might reveal, or come to reflect on, its own essence. I argue later that this is the technological condition in which we now find ourselves.

I then turn to Bernard Stiegler's extension of Heidegger's theory of technics through the concept of grammatisation - for me best explained in his 2013 article on enlightenment in the digital age: 'Die Aufklarung in the age of Philosophical Engineering'. ${ }^{6}$ This concept of grammatisation is a fusion of Derrida's 'grammatology' with Heidegger's technics. ${ }^{7}$ Where language for Derrida both limits and enables our capacity to think, it is seen by Stiegler as only one technology/techné amongst many that reduces behavioural flows or fluxes into meaningful and reproducible forms. Through these forms is expressed and imprinted all of human experience - for Stiegler all modes of 'speaking, working, perceiving, interacting and so on'.

In its basest form this is simply the systematisation and repetition of expressive bodily gestures which directly mimic real actions. Speech forms are 
then the grammatisation of all possible sounds emanating from the voice box. Writing then subsequently develops as a grammatisation of vocal expressivity into graphic forms. Stiegler refers to this process as a spatialisation and thus a temporalisation of basic behavioural fluxes. When speech is written down it becomes spatial, and thus sequentialised it gains a temporality as a meaningful operational flow. It is also a materialisation, but one which does not assume some pre-existing immateriality, it is just materialisation, then a rematerialisation and another re-materialisation, and so on. ${ }^{9}$

The only way we can perceive and understand things is through these material forms. We can of course can talk about an ontological firstness - the immanent and essential flux to which Steigler and many others (Deleuze, Peirce, Lacan, Hegel) directly and indirectly refer - but this firstness is essentially unknowable without some element of materialisation into recognisable and repeatable forms - as secondness and thirdness in Peirce's analysis in On a New List of Categories. ${ }^{10}$

It is on this point of firstness that Stiegler departs from Heidegger to a certain extent. Where Heidegger assumes an originary 'nature' or physis, a natural or pure state from which we depart and grow farther from through our engagement with technology, Stiegler states in almost Foucauldian terms that there is no primal or originary state, no 'truth', just different and ambivalent grammatisations and materialisations taking shape out of the immanent flux.

After writing, printing processes, painting and film, each being specific technologies of spatialisation and materialisation, we have digital media. Stiegler calls all of these forms tertiary retentions, where mental and behavioural flows are fixed in material, external and discrete forms 'ideograms, manuscripts, texts, prints, records, databases, metadata and so on,' depending on the epoch. ${ }^{11}$ These forms become shared memories - mnemonic mental prostheses - and they are by definition technical in the Heideggerian sense, but they are also increasingly defined by being actual technological machine systems, i.e. computers.

So these technological systems are not just storage of memory and information in databases, or communication technologies like email, or even the internet seen as a complex information system, they are also the means by which stories, histories and cultures are shared and imaginations projected. It is for Stiegler our 'mental reality...projected onto a support that is neither cerebral nor psychic but technical'. ${ }^{12}$ As such the entertainment media industry - the industry of the sharing of mental realities - is also very much part of this technical system.

As Heidegger points out, this can be seen in an instrumental mode that we create this technology simply to help us remember - but we also know that it alters us in our capacity to remember. Entertainment media do not only entertain, they also condition and educate through affective 'distracted' means. They alter our behaviour in very real and tangible ways, but also alter our brains in ways that are increasingly understood through researches into neuroplasticity and the malleability of our mental circuitry - as Gilles Deleuze suggested in his Cinema books, ${ }^{13}$ and has been further developed through the work of others such as the philosopher of neuroscience Catherine Malabou. ${ }^{14}$

The ethical concern for Steigler is that our mental process are 'shortcircuited' - the digital technical systems are too automated, they do too much for us, and thus, we do not think properly for ourselves. In his words: 'Automisation makes digitalisation possible, but although it immeasurably increases the power of mind (as rationalisation) it can also destroy the mind's 
knowledge (as rationality). ${ }^{15}$ We can think of this as actual physical changes in the brain parallel to processes of abstract thought.

It is here that I develop a critique of Stiegler; for where he sees an insidious and corrosive effect on the mind due to these 'invisible automatisms', I instead see emergent properties of these very same automatisms, which reveal to us something new, and which re-educate us through our apperception (in that distracted state to which Benjamin refers) towards new intuitions and new perceptions of reality. This, for me, is the 'revealing' potential of digital visual technologies, and it is this that I wish to address as perhaps being the other possibility of Heidegger's 'saving power'.

I now wish to look at some examples of this 'revealing', initially through the digital cinematic image. These are entertainment images, yet to my mind they expose something that does not necessarily inhere in the imagination of the director, DOP, or technician as during the production of the work. This is the uncanny, or sublime quality of digital visual effects, which I would argue creates sensations and intuitions within the body which cannot be explained or contained by talking only about the authorial intention of the creator. It is not simply a wonder at the mastery of technology, but rather an affectively intuited and subtle change in ones' sense of the world as a consequence of a truly original image.

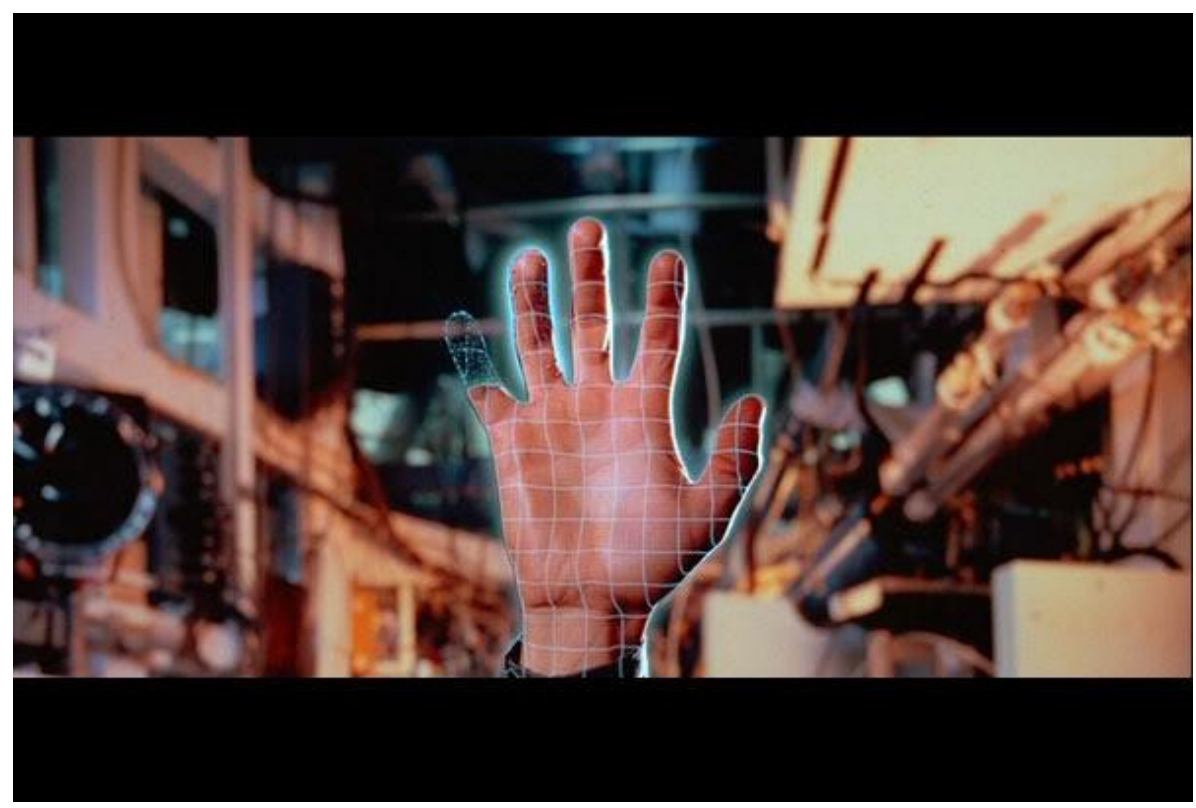

Figure I. Screen shot from Tron 1982 Director Steven Lisberger. Walt Disney Productions.

My first example is the uploading of the character Flynn into the digital game world in the original 1982 film, Tron (dir. Steven Lisberger). In this 'digitisation' scene the protagonist dematerialises by the action of a laser and travels through a vivid digital non-space of grid patterns and 'rabbit hole' vortexes, to rematerialize within the game world (figure 1). There is a sense of floating weightlessness in the space between the real world and the digital game space, and a real corporeal affection of a body (subject) dispersed within a digital liminality. The same affect, or affective intensity is not there for all people I am sure, but this image for me in 1982 (or whenever I first saw it) was a truly novel image and I think it still holds up well today. Perplexingly, they did not include an equivalent 'inter-space' scene in the 2010 update of the film Tron: Legacy (dir. Joseph Kosinski), despite the ironic actual digitisation of actor 
Jeff Bridges to render a virtual, younger version of his character - Flynn's alterego $\mathrm{Clu} .{ }^{16}$ The journey between spaces is rendered as within an instant, perhaps qualified by faster data transfer speeds, but in fact explained by the director to firstly be a deliberate choice to not compete with the scene of the first film and secondly to portray it from the perspective of the character, 'through Sam's eyes'. ${ }^{17}$

A second 'historical' example is The Matrix's (dir. Lana Wachowski 1999) rendering of a reality constructed of code. This is perhaps a bit of a clichéd image within new-media studies, but I refer to it because it contains very striking images of an altered materiality and temporality, with the morphing bodies of the 'agents' and with spaces rendered as streams of coding. The film further involves the famous 'bullet time' digital morphing effect added to an old multi-camera photographic trick from the pre-cinematic time of Etienne Jules Marey and Eadweard Muybridge. ${ }^{18}$ With this effect we see the smoothing (or interpolation) of continuous movement by the insertion of extra digitally altered frames between the already closely spaced photographic shots. As with Tron, there is an expanded sense of duration, and within this an uncanny dislocation from our sense of the real world, a kind of metaphysical 'estrangement'. ${ }^{19}$

This image also provides a useful segue into talking about the cinematic morph in general. The idea given in both Tron and in the The Matrix is that matter is transferrable into data, and as such, it can change in space and time. While the photographic index provided a metaphysical assurance of the stability of material reality, the digital image gives us no such confidence as all matter is converted into undecipherable ones and zeros within the machine. This is a concept that arises with the digital - that data is immaterial electrical signals, and that there are somehow immaterial landscapes of data within the hard drive. Matter and data struggle to coexist ontologically, bound together only by our consciousness of them, or our ability to imagine their relative materiality. The morph clearly shows data changing matter in space and in time, even though this is still just a imaginative projection at this point - i.e not actual real world phenomena.

This develops into a thematic preoccupation in much obviously digital cinema content. We have seen Jonny Depp's consciousness uploaded into a computer in Transcendence (dir. Wally Pfister, 2014) where he becomes godlike and can subsequently control matter. Similarly in Luc Besson's Lucy (figure 2), Scarlett Johansson's brainpower is increased exponentially by an experimental drug, so that she can see and pluck digital data from the air. In contemporary digital effects media there is now a practical obsession with 'superpowers' which function as metaphors for the powers of the user/programmer within digital space.




To turn now to real world phenomena, let us consider 3D printing as a kind of projection within a volumetric screen space. Here it seems that pure data is converted almost instantly into real matter. An object which has only ever existed within the computer in virtual form suddenly materialises before our eyes, layer upon layer, and without a present intermediary in the form of craftsman or technician. The technical craft here is essentially automised and invisible. Recently we have seen astounding 3D printed fashions on the likes of Dita von Teese and on Iris Van Herpen's catwalks - apparently pure flights of imaginative fancy rendered physically real at the click of a mouse. Furthermore, 3D printed houses in China have been proposed as a solution to a housing shortage and are being produced at the rate of ten per day - a kind of sudden, automatic materialisation of living-spaces.

Not unconnected, the holographic image traces with light what the 3D printer does with solid materials. An image is trapped within a volumetric material substrate, usually glass, through the interference patterns of two lasers, and when light is shone again through that substrate a three dimensional image appears. Fascinatingly, when broken into pieces each fragment of the glass substrate contains the entire image, with each point on the material containing all of the data for the entire image. Here the complexity of data storage in depth stretches our capacity to understand beyond the photographic materialisations with which we are familiar. Each piece of the glass provides a multiplication of points of access to the immanent data. Holography is apparently the future for data storage in general, with radically increased $\mathrm{read} /$ write speeds and much greater storage capacity within a smaller space up to four terabytes within a one-inch cube according to recent reports. ${ }^{20}$

Consider also the relatively recent Musion Eyeliner holographic projection system, where virtual presence is achieved by the digital updating of the old Victorian Pepper's ghost stage trick. ${ }^{21}$ This kind of 3D telepresence has had applications mainly within corporate events, as well as in various virtualised fashion shows, award ceremonies and marketing events, but has achieved greater public visibility through events such as the 'bringing back to life' of Tupac Shakur, seen clearly present on stage with Snoop Dogg at the 2012 Coachella festival. ${ }^{22}$ Though merely a holographic 3D effect, rather than true holography, the illusion of real presence with the Musion system works so well that it is easy to create a powerfully uncanny impression when the image of a body is digitally distorted by either slowing it down or dissolving it into atoms as in one particular performance by the Black Eyed Peas at the French NRJ awards. ${ }^{23}$

Finally, I make an example of 3D projection mapping. This visual art practice developed out of simple DIY applications only about 6 years ago, but has quickly become big business in marketing events and product launches, as well as being a staple of club visuals and son-et-lumiere festivals worldwide. Three-dimensional models of real objects and buildings are constructed within a program and then a different image is projected onto each of the those dimensions. Very solid objects can apparently then be made to morph, throb, collapse or appear transparent. Here, any object of any scale becomes a public screen onto which a virtual dimension is projected, in a process by which the real materiality of that object is interrogated - perhaps by inference the materiality of all objects.

In all of these above examples of digital 'revealing' we have clear breaches of our normal habits of perception: some simple perceptual tricks, 
some highly technologised processes, and some barely explicable automated processes. All are fundamentally dependant on digital technologies and processes through the relative materiality of data. Furthermore, these sensations and perceptions are cultivated not through distanced analytical study, but often through intense corporeal affections in increasingly immersive visual and aural environments. Very soon we will also see the ominous return of virtual reality in the form of Sony produced Morpheus, and Kickstarter funded Oculus Rift goggles for gaming - a natural extension, and perhaps conclusion, of the new default digital image regime of immersive visual and aural media that cinema theorist Thomas Elsaesser accurately describes in his 2013 article on the logic and genealogy of digital 3D. ${ }^{24}$

\section{Conclusion}

Digital images seem to drift ambivalently and automatically towards images of metaphysical flux, and I would argue that this is due to their ambiguous material and ontological status relative to previous grammatised media forms, whose emphatic materiality clearly lent itself to specific metaphysical reflections (in film's case to an explicit reflexivity on temporality, memory and mortality). We cognitively and affectively experience a breach of the boundary between materiality and code, and through this I propose we increasingly come to intuit 'reality' to be of or like data - subject to fluctuation, modulation or even dramatic change and reversal. How well do we police these ontological boundaries within our psyche? Does this not create a metaphoric resonance with our general knowledge of quantum physics, atoms, quarks and dark matter within our corporeal mind? How could our operational mental simulations of the world not be tinted by these experiences?

This leads me to question: when does a digitally augmented reality become just 'normal' reality as per our 'distracted' apperception of it? Rather than digital media dragging us farther away from nature, does it not re-write nature itself? It reveals the world to us in unforeseen ways, stimulates thought about certain metaphysical aspects and subsequently alters our capacity to corporeally and 'naturally' intuit certain underlying essences of reality, not least in the way we think about the digital and digital processes themselves.

Digital media proves then to be a grammatisation unlike any other grammatisation before it - it is a grammatisation of existence as such. It does not so much create fixed images of reality, but instead simulates reality in increasingly complex ways, as feedback systems, and in ways that overlay and merge with the 'old' reality - as I say, an augmented reality.

As Stiegler notes correctly, all grammatisations function as pharmaka they enable as much as they restrict, both poison and cure. ${ }^{25}$ Popular discourse has it that certain digital functions, while ostensibly assistive, are in some ways socially, psychologically or even physically detrimental. However, we can also look towards a future of the digital, which continues to reveal the world to us in novel and emergent ways. The ethical nuance of this will always be that the world as presented through the grammatisation of the digital certainly seems a little less consistent.

So my final point returns to Heidegger's 'other possibility' - that the 'saving power' arrives not as some antithesis to the enframing power of technology, but rather through the technology itself, in its ubiquity, in starting to achieve the same aesthetic effect - it reveals its own truth. In the case of digital technology this truth is not a return to an idealised 'nature', but perhaps rather the revelation of an underlying immanent flux of information, as well as 
the grammatised habits by which things become materialised and humans individuated. These are also fundamentally natural processes in that, according to Stiegler, there was never anything else.

\section{Goldsmiths College}

\section{Notes}

$1 \quad$ Walter Benjamin, 'The Work of Art in the Age of Mechanical Reproduction', in Illuminations, ed. by Hannah Arendt, trans. by Harry Zohn (London: Pimlico [Vintage], 1999).

2 Cosmological holography or holographic universe theory, proposed by theoretical physicist Gerard 't Hooft, then appropriated and explained in lay (quasi-spiritual) terms by Michael Talbot, suggests that that matter, energy, time and space are merely projections from some underlying dimension of reality that we are not privy to, such that we cannot think of things as separate parts or entities, as each part relates back to the whole. The universe is imagined in this way as pure information, organised by holographic principles and projected from an external source. Michael Talbot, The Holographic Universe: The Revolutionary Theory of Reality (London: Harper Collins, 1991). Martin Heidegger, The Question Concerning Technology, trans. by William Lovitt (New York: Harper Perennial, 1977).

Martin Heidegger, pp. 28, 34.

Martin Heidegger, p. 35.

Bernard Stiegler, 'Die Aufklarung in the age of Philosophical Engineering', in Digital Enlightenment Yearbook 2013, ed. by M Hildebrand and others, trans. by Daniel Ross (Amsterdam: IOS Press, 2013).

Jacques Derrida, On Grammatology (Baltimore: John Hopkins University Press, 1974). Stiegler, p. 32.

Stiegler, p. 33.

For Deleuze, via Peirce, this ontological Firstness is seen as a 'plane of immanence', for Lacan it is the 'Real', and for Hegel in his Philosophy of Subjective Spirit it is the immediate material of sensation, which must be organized into meaningful habits. It refers to an undifferentiated mass of potential actions and meaning, as yet unrealised and unactualised. Secondness and Thirdness then refers to the recognition, repetition and systematization of primal and synaesthetic sensations and vitality forms from this 'flux'. Charles S Peirce, The Philosophy of Pierce: Selected Writings, ed. by J. Buchler (New York: Harcourt Brace, 1940). Georg Wilhelm Friedrich Hegel, Hegel's Philosophy Of Subjective Spirit, ed. by M. J. Petry (Dordrecht, Holland: Reidel, 1978). Stiegler, p. 34.

Stiegler, p. 34.

Gilles Deleuze, Cinema 1: The Movement Image (Minneapolis: University of Minnesota Press, 1986); and Cinema 2: The Time Image (Minneapolis: University of Minnesota Press, 1989). Catherine Malabou, What Should We Do With Our Brains?, trans. by Sebastian Rand (New York: Fordham University Press, 2008).

Stiegler, p. 38.

In interview with the Den of Geek magazine the producers of Tron: Legacy, Justin Springer and Steven Lisberger, discuss this irony:

'JS: In Tron there's a famous scene of Jeff Bridges being digitised and put inside a computer. And when we began working on Tron: Legacy, and we started to create Clu, we put Jeff in front of a laser and basically digitising him to go inside the system. [laughs]

SL: ...and I'd made that up! That was a pain in the ass 28 years ago!

JS: Jeff was like, "This is wild, man!"

SL: And then the technicians that were doing the scanning didn't appreciate the irony. I said, "Don't you realise I just made that up all those years ago!" and they said "You made it up, so of course it came true this way."

$<$ http://www.denofgeek.com/movies/21185/interview-justin-springer-and-stevenlisberger-co-producers-of-tron-legacy\#ixzz3EKbAyEYB > [accessed 25 September 2014]. 
17 Tron: Legacy director Joe Kosinski: “From the beginning we kind of didn't wanna do that, cause it was done so well in the first one. I wanted this experience to be different, so I liked the idea that you kind of experience it with Sam and it's a quick thing." $<$ http://collider.com/joseph-kosinski-interview-tron-legacy-tron-3-reshoots-eastereggs/ $>$ [accessed 25 September 2014]. invention of the moving image. At around the same time in the 1870s in France and America respectively, they developed different technologies for the photographic capture of closely sequential images - a proto-cinematic process. Marta Braun, Picturing Time: The Work of Etienne Jules Marey (Chicago: University of Chicago Press, 1992).

19 Though this is not an estrangement (distancing) from the diegetic film world, rather from the world outside the movie theatre. It is the 'real' world here that is 'made strange'.

20 See for instance: Kevin Curtis, with Lisa Dhar and others, Holographic Data Storage: From Theory to Practical Systems (Chichester: John Wiley, 2010).

21 The Pepper's Ghost illusion was achieved by an invisible sheet of glass being suspended at 45 degrees in front of the stage. Figures lit up in the space of the orchestra pit would be reflected in the glass and would appear as ghostly apparitions on the stage. With the new digital Musion system this illusion is rendered far less ghostly, with a bright projected image being reflected off of a transparent foil. See

22 See the website for Musion at www.eyeliner3d.com for more of these applications and uses .

$23 \mathrm{http} / / /$ musion.com/?portfolio=black-eyed-peas-holograms-at-nrj-awards-show [accessed 25 September 2014]. Thomas Elsaesser, 'The "Return" of 3-D: On Some of the Logics and Genealogies of the Image in the Twenty-First Century', Critical Enquiry, 39 (2013), 217-246. Stiegler, p. 31.

\section{Works Cited}

Benjamin, Walter, 'The Work of Art in the Age of Mechanical Reproduction', in Illuminations, ed. by Hannah Arendt, trans. by Harry Zohn (London: Pimlico [Vintage], 1999)

Braun, Marta, Picturing Time: The Work of Etienne Jules Marey (Chicago: University of Chicago Press, 1992)

Deleuze, Gilles, Cinema 1: The Movement Image, (Minneapolis: University of Minnesota Press, 1986) Cinema 2: The Time Image (Minneapolis: University of Minnesota Press, 1989)

Derrida, Jacques, On Grammatology, (Baltimore: John Hopkins University Press, 1974)

Elsaesser, Thomas, "The "Return" of 3-D: On Some of the Logics and Genealogies of the Image in the Twenty-First Century', Critical Enquiry, 39 (2013), 217-246

Hegel, Georg Wilhelm Friedrich, Hegel's Philosophy Of Subjective Spirit, ed. by M. J. Petry (Dordrecht, Holland: Reidel, 1978)

Heidegger, Martin, The Question Concerning Technology, trans. by William Lovitt (New York: Harper Perennial, 1977)

Malabou, Catherine, What Should We Do With Our Brains?, trans. by Sebastian Rand (New York: Fordham University Press, 2008)

Peirce, Charles S., The Philosophy of Pierce: Selected Writings, ed. by J. Buchler (New York: Harcourt Brace, 1940) 
Stiegler, Bernard, 'Die Aufklarung in the age of Philosophical Engineering', in Digital Enlightenment Yearbook 2013, ed. by M Hildebrand and others, trans. by Daniel Ross (Amsterdam: IOS Press, 2013)

Talbot, Michael, The Holographic Universe: The Revolutionary Theory of Reality, (London: Harper Collins, 1991) 